\title{
nature
}

\section{Paying the price of health care}

The British government's plans to reorganize its public health service are not as fearsome as its critics say, but endanger medical research - and the civility that health care has brought to Britain.

Aвоuт the only certainty in the business of health care is that the cost will always increase more quickly than it can be afforded. The explanation is both simple and familiar. Broadly speaking, better health implies longevity, meaning that a person's chance of living to debilitated old age is increased, so that the proportion of people needing care of some kind grows with the passage of time. So do people's expectations. One decade, they may be reconciled to the view that the best treatment for heart disease is its avoidance (exercise, sensible diet and so on), the next they will be looking for coronary by-pass operations when they need them, which means that age-specific unit costs also tend to increase. Of course, there are some countervailing tendencies. As healthier people live longer, morbidity and thus the need for health care at a given age may decline. In most industrialized countries, this has been one of the outstanding demographic phenomena of the past few decades.

And the unit cost of even coronary by-pass operations declines as more of them are performed, although that does not imply that the total cost of heart surgery stops growing. But experience seems to show that tendencies towards increasing costs predominate.

These familiar considerations are essentially why the British government has spent more than a year deciding how best to put its National Health Service on a different and, with luck, more stable financial footing. That, at least, is the government's view of its intentions. Its critics would prefer that it were understood that the year has been spent searching for ways of reducing the cost to the public purse of the National Health Service (NHS), now twice the annual defence budget. The truth is that the issue is not simply economic, but political. In general terms, the British government believes that public spending should be a minimum; the opposition parties that the present government spends too little on helping society tick over. The difference of opinion also goes back to the origins of the NHS, which was founded (in 1947) by a Labour government and which has been managed for more than half of the intervening time by governments of a different persuasion. But the outcome of the government's study, a set of recommendations for discussion, will disappoint its friends as well as its opponents.

\section{Inspiration}

The British NHS has a special place in recent social history. Its inspiration, in the impoverished 1920 s and 1930s, was the belief that people should not be denied access to medical care for lack of funds. The method chosen in 1947 to put this principle into practice was to declare that medical treatment should be free of charge to all who asked for it. Aneurin Bevan, the Cabinet minister who pushed the legislation through the British Parliament, believed there would be such a rapid improvement of the general health of the British population that the costs of free treatment would at worst remain static. Forty years of experience have shown that the NHS has had a powerful influence on the temper of British society. The elderly and the chronically sick have been cared for without regard for their personal resources. As it happens, other sections of British society have delighted in the NHS: a little to the present British government's embarrassment, many of its own supporters are also among the strongest supporters of what has been called elsewhere a system of "socialized medicine".

The upshot of the government's new proposals for the NHS is not radical but managerial. The government has backed away from its earlier hopes that it might find ways of shedding part of the cost of the NHS to other independent sources of funds - the pockets of patients through compulsory health insurance, for example - and has opted instead for a strategy for making the NHS much more efficient. Major hospitals are to be allowed to contract out of direct control by regional health authorities, while family physicians in sufficiently large practices will be encouraged to work within an annual budget and allowed to keep half of whatever costs they save. The opposition parties regard this as a first step towards complete devolution of government responsibility for the NHS, but that is an issue for a future Parliament - and the proposed reforms will not be complete until 1992 or later. The more serious difficulty is that the changes, if they work, will yield a once-and-for-all benefit, but not solve the long-term problem occasioned by the disproportionately rapid increase of costs.

\section{Danger}

Meanwhile, the changes now planned are likely to damage some important functions of the NHS as it has evolved, responsibility for research and innovation in particular. Under the present system, the Medical Research Council (MRC) has funds for the support of basic medical research, but parts of NHS, in partnership with the MRC or otherwise, supports the development of new techniques by meeting the costs out of current budgets. What will happen when the major hospitals in which this work inevitably concentrates will be autonomous but driven by the need to balance their books, and to keep their costs within reasonable limits so as to compete with other hospitals? There is at least a danger that research projects will go to the wall. Before the changes planned have made much headway, the government may find itself having to create a second source of research funds - or contemplate the possibility that British medicine will lag behind that elsewhere?

The other obvious danger is that the new regime will prove one in which the people most in need of treatment will find themselves, for lack of personal resources, at the end of whatever queues there are. Although the government says that there is no intention of departing from the principles on which the NHS is run at present, last week's proposals say nothing about the mechanism by which this is to be done. The elderly and the chronically sick will be, in relation to the new NHS, in much the position of the consumers of the newly privatized nationalized industries - less able to exercise their rights as consumers than they should be. That is why even the modest changes in the management of the NHS now proposed demand ways in which the interests of the patients least able to look after themselves can be safeguarded.

If such a mechanism is not provided, the government will find that - contrary to its expressed intentions - the civility that the NHS has brought to British life will be put in hazard. 